\title{
Metastatic ovarian tumor of a lung cancer at the hospital center of Chauny (France): a case report
}

\author{
Adjoby Cassou Roland ${ }^{1}$, Kouamé Arthur Didier ${ }^{1 *}$, Koffi Achille ${ }^{1}$, Kakou Charles ${ }^{1}$, \\ Konan Joachim', Andriamandimbison Zoly ${ }^{2}$, Ahounkeng Patrick ${ }^{2}$, Nshimirimana Eric ${ }^{2}$
}

\begin{abstract}
${ }^{1}$ Department of Obstetrics and Gynecology, University Hospital Center of Cocody, Abidjan, Côte D'Ivoire
${ }^{2}$ Department of Obstetrics and Gynecology, Hospital Center of Chauny, France
\end{abstract}

Received: 14 September 2017

Accepted: 16 September 2017

\section{*Correspondence:}

Dr. Kouamé Arthur Didier,

E-mail: Arthur.kouame@mail.huji.ac.il

Copyright: () the author(s), publisher and licensee Medip Academy. This is an open-access article distributed under the terms of the Creative Commons Attribution Non-Commercial License, which permits unrestricted non-commercial use, distribution, and reproduction in any medium, provided the original work is properly cited.

\begin{abstract}
The ovary is an organ that can be the site of metastases for many cancers. In general, malignant ovarian tumors are primary; however, cases of extra gynecological metastatic tumors (breast, colon, stomach, and pancreas) have been reported. In most cases, the primary cancers of these ovarian tumors are gastrointestinal or gynecological, the lung being very rarely involved. We report a rare case of ovarian metastases of bronchial cancer discovered during an extensional assessment. The histological examination coupled with immunohistochemistry concludes that ovarian metastasis of small cell lung carcinoma. In addition to chemotherapy such as Taxol-Hycamtin, the management required cerebral radiotherapy for a cerebral metastasis detected.
\end{abstract}

Keywords: Metastasis, Napsin A, Ovary, Small cell lung carcinoma

\section{INTRODUCTION}

Every year around the world, ovarian cancer is diagnosed in approximately 200,000 women and 115,000 women die from it. ${ }^{1}$ Ovarian cancers are the sixth most common cancer in women and constitute $4 \%$ of cancer deaths occurring in the majority of cases in the post-menopausal period. Mortality rates in developed countries exceed 5 per 100,000 women. ${ }^{2}$

In general, malignant ovarian tumors are primary, although cases of metastatic extra gynecological tumors (breast, colon, stomach, pancreas) have been reported in $6 \%$ to $22 \%$ with a gastrointestinal predominance. ${ }^{3}$ Bronchial metastases represent $2 \%$ to $4 \%$ of metastatic ovarian tumors. ${ }^{4} \mathrm{We}$ report a rare case of bronchial cancer with ovarian metastases and discuss the diagnostic and therapeutic aspects.

\section{CASE REPORT}

A 52-year-old patient is admitted to the Pneumology department of Chauny Hospital Center for investigation of recurrent pneumonia. This is a third 3rd gesture and 3rd parous woman who smoked 10 cigarettes per day for 17 years. She does not have a real gynecological followup. There is no oncological history in her family. In the course of respiratory system assessment, the chest CT scan showed a pre-atelectatic opacity, a left pleural reaction, with an infiltrate in the mediastinal region, associated with a repression of the right atrium and the left upper pulmonary vein (Figure 1). In PET SCAN, lymphadenopathy under hyperintense metabolic pathways is objectified with a left pulmonary hilar ganglio-tumor mass with moderately hypermetabolic pulmonary condensation downstream of the left hilar ganglio-tumor mass. 


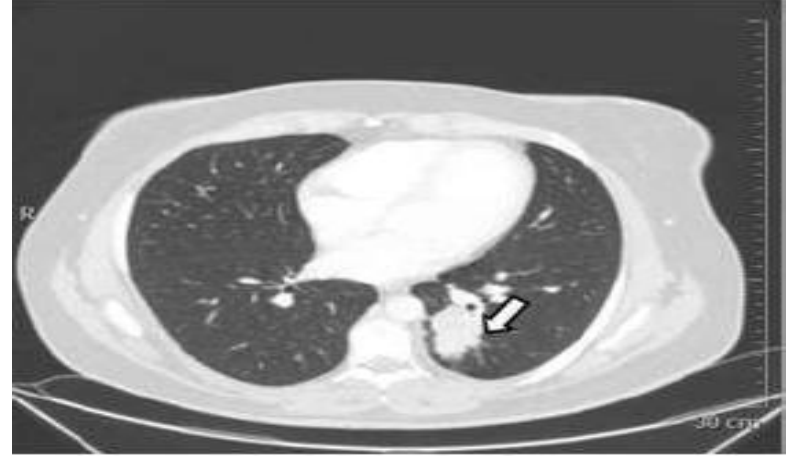

Figure 1: CT scan showing the primitive tumor of the lung.

The bronchial fibroscopy performed was in favor of an infiltration with respect to the spur of the left lower lobe with stenosis at the entrance. A biopsy on a tumor area of the upper left lobe is done, and the histology concludes with small cell lung carcinoma. The treatment was based on 2 cycles of chemotherapy (Paclitaxel-CarboplatinDoxorubicin-Endoxan), 2 cycles of carboplatin-VP16 and a radiochemotherapy Carboplatin-VP16. Relative clinical improvement was observed with encouraging results on MRI, PET-SCAN: reduction of the volume of infiltration, lymphangitis symptoms and the volume of the lymph node under carini.

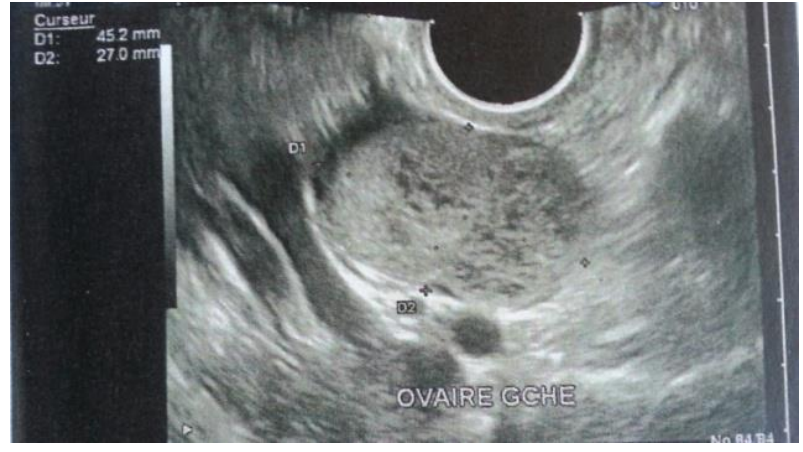

Figure 2: Pelvic ultrasonography scan showing a heterogeneous left ovary.

Three months later, the patient consulted her gynecologist for heaviness pelvic pain. The gynecological examination found a left lateral uterine mass. A pelvic ultrasound carried out allows the visualization of an organic mass developed at the expense of the left ovary (Figure 2). Ovarian tumor markers check were normal $(\mathrm{ACE}=1.13$ ng/ml; CA 19-9 = $10 \mathrm{U} / \mathrm{ml}$; CA $125=12 \mathrm{U} / \mathrm{ml})$. A PET SCAN carried out for the work-up for extension showed a Hypermetabolic ovarian lesion with a strong suspicion of cerebral and left adrenal invasion. Laparoscopy revealed an inflammatory pelvis, adhesions preventing the right adnexa from being observed and an enlarged left ovary without extracystic vegetation.

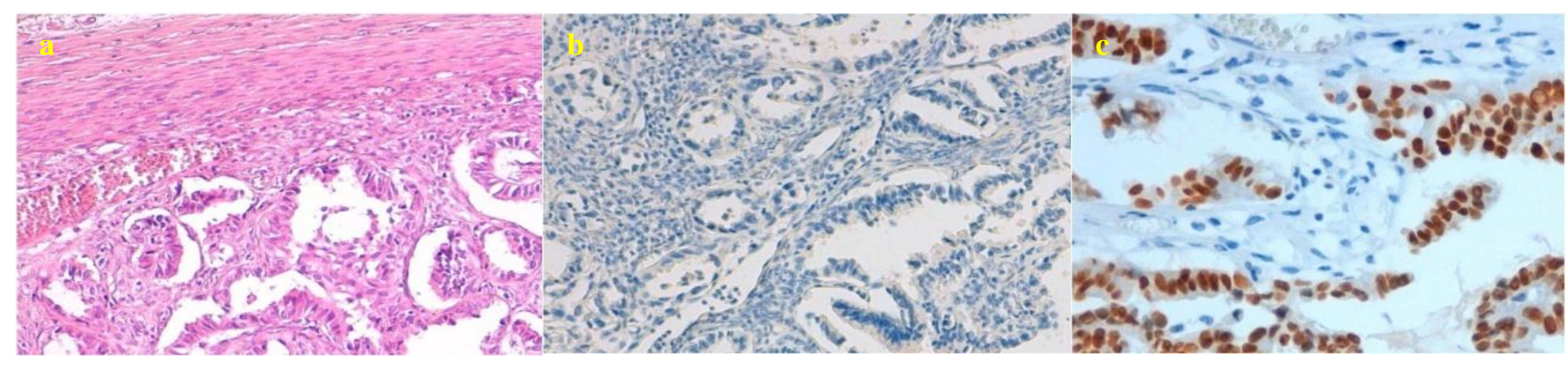

Figure 3: histological images showing a metastasis of small cell lung carcinoma a): Ovarian metastasis (X 250), b): Ovarian metastasis with TTF-1 profound expression (X250), c): Ovarian metastasis, no TTF-1 expression (X 250).

Omentum and peritoneum biopsy, cytological specimens and left adnexectomy were performed. The histological report concludes that ovarian metastasis of a slightly differentiated bronchial cancer with a high mitotic activity (>50 mitoses/10champs), ki67 up to $60 \%$, a strong intra nuclear positivity with TTF1 (Thyroid Transcription Factor-1) and negative anti chromogranin (Figures 3a, b and c).

Given this dark prognosis, cerebral radiotherapy and chemotherapy such as Taxol-Hycamtin (paclitaxeltopotecan) with CT scan and PET SCAN are planned after 3 cycles.

\section{DISCUSSION}

Bronchial cancer is a tumor with a high metastatic potential, with a predilection for the liver, the brain and the adrenal glands. Metastasis occurs through several mechanisms, including direct extension of neighboring organ cancer, transtubal migration of endometrial cancer, dissemination through the peritoneal fluid or by vascular invasion. Indeed, the absence of capsular invasion as well as the vascular, lymphatic or venous invasion supports a lymphatic and hematogenic pathways of extension. 5,6 
Its dissemination in the genital tract rarely occurs with variable effects in the literature; At an average age of 47 years with extremes of 26-76 years. ${ }^{4,7}$ In a North American study of 500 cases of ovarian tumors, $17 \%$ were metastatic versus $22 \%$ in a Turkish study of 186 cases of ovarian tumors. ${ }^{8}$ A large Chinese study of 10288 cases of metastatic ovarian tumors reported a bronchial origin in $10 \%$ of cases. ${ }^{9}$ Fujiwara et al., in an analysis of 313 patients with ovarian metastases, found only one case of primary bronchial cancer. ${ }^{10}$

Metastatic ovarian cancers of non-gynecological origin are ten times more frequent than those from the genital tract, with adenocarcinomas of the gastrointestinal tract leading. ${ }^{11,12}$ In a recent study of 166 patients with nongynecologic malignancies and adnexal masses, Kim et al. found $68 \%$ of ovarian metastases. These masses can be the first clinical manifestation of the malignant tumor, thus a source of diagnostic error of the true primary tumor, even after pthatological examination. ${ }^{13}$ Indeed, an extra-genital primary cause was found in $17 \%$ after ovarian mass surgery and $38 \%$ in another study, in an interval of 4 days to 7 months. ${ }^{12,14}$ Some determinants of metastatic disease are known: high-grade tumor, diffuse peritoneal and omental involvement and invasion of retroperitoneal nodes. ${ }^{3}$ By itself, bronchial cancer is involved in $2-4 \%$. However this rate is increasing. ${ }^{4}$ In cases already described, small cell carcinoma was the most histologic type reported (43\%) followed by adenocarcinoma (32\%), more rarely large cell carcinoma, composite carcinoma and atypical carcinoid tumor. ${ }^{4,12}$ Ketata et al. In a study, reported 37 cases of total ovarian metastases listed in various studies worldwide. In the diagnosis sequence, some authors initially observed metastases in six cases, synchronous discovery with the primary tumor in 16 cases and secondary to the discovery of the primary tumor in 15 cases. It is often unilateral (27 of 37 cases). In $10 \%$ of cases, coexistence of a primary and metastatic tumor was noticed on the ovary. ${ }^{15}$

Clinical diagnosis of metastatic ovarian tumor is never easy; Often accidental discovery, but sometimes symptomatic with manifestations of palpable mass, menometrorrhagias or pelvic pains that was the case in our observation. Ultrasound is the first-line examination before a pelvic mass and will specify its cystic or solid nature (partitions, vegetations) wall state, vascularisation, existence of a peritoneal collection. MRI is currently the reference tool for characterizing the ovarian masses: cystic lesions appear in hyper signal T2 and hypo signal $\mathrm{T} 1$, whereas tissue lesions are intermediate signal and enhance after gadolinium injection. ${ }^{16}$

In present study, imaging evoked an ovarian tumor. The exact nature was specified by pathological examination of a piece taken during an operative laparoscopy. Differentiation between primary and metastatic ovarian tumors remains problematic. In principle, tumor expression for TTF1 (thyroid, lung and diencephalon- specific gene transcription protein) and CA 125 negativity are in favor of a primary pulmonary tumor.

The diagnosis of small cell carcinomas is based on morphological and immunohistochemical data by expression of neuroendocrine markers (chromogranin and synaptophysin). ${ }^{9,17}$ In the immunohistochemical arsenal, another protein: Napsin A expressed on pneumocytes type II and alveolar macrophages, would be a complementary tool. It distinguishes primary bronchial adenocarcinomas from adenocarcinomas from other organs or metastatics. ${ }^{18}$ Thus, the combination of Napsin A and TTF-1 would increase sensitivity and specificity in the authentification of pulmonary origin of metastatic adenocarcinomas. ${ }^{19}$

\section{CONCLUSION}

Clinicians should be mindful of a metastatic event before any ovarian tumor with atypical clinical and anatomopathological features. Moreover, with the recrudescence of bronchial cancers in women, the pulmonary origin of the metastatic ovarian masses should be sought and in this approach TTF-1 would be unavoidable.

\section{ACKNOWLEDGMENTS}

Authors would like to thank patient for giving her consent to publish the case.

\section{Funding: No funding sources \\ Conflict of interest: None declared \\ Ethical approval: Not required}

\section{REFERENCES}

1. Mei L, Chen H, Wei DM et al. Maintenance chemotherapy for ovarian cancer Cochrane Database Syst Rev. 2010 sept 8;(9):CD007414.

2. Sankaranarayanan R, Ferlay J. Worldwide burden of gynaecological cancer: the size of the problem. Best Pract Res Clin Obstet Gynecol. 2006;20(2):207-25.

3. Hart WR. Diagnostic challenge of secondary (metastatic) ovarian tumors simulating primary endometrioid and mucinous neoplasms. Pathol Int. 2005;55(5):231-43.

4. Irving JA, Young RH. Lung cancer metastatic to the ovary: a clinicopathological study of 32 cases emphasizing their morphology spectrum and problem in differential diagnosis. Am $\mathrm{J}$ Pathol. 2005;29:997-1006.

5. Kalir T. Metastatic tumors of ovary diagnosis and management of ovary disorders of metastatis of ovary. Gynecol Oncol. 1995;59:124-8.

6. Malviya VK, Bansal M, Chahinian P, Deppe G, Lauersen N, Gordon RE. Small cell anaplasic lung cancer presenting as an ovarian metastasis. Int $\mathbf{J}$ Gynecol Obstet. 1982;20:487-93. 
7. Botana Rial M, Fernandez-Villar A, Gonzalez Pineiro A, Leiro Fernandez V. Primary lung adenocarcinoma with ovarian metastasis: a rare presentation of bronchogenic carcinoma. Arch Broncopneumol. 2009;45(11):571-2.

8. Demopoulos RI, Touger L, Dublin N. Secondary ovarian carcinoma: a clinical and pathological evaluation. Int J Gynecol Pathol. 1987;6(2):166-75.

9. Yeah KY, Chang JWC, Lin MC. Ovarian metastasis originating from bronciolalveolar carcinoma a rare presentation of lung cancer. $\mathbf{J}$ Clin Oncol. 2003;33:404-7.

10. Fujiwara K, Ohishi Y, Koike H, Sawada Y, Moriya T, Kohno I. Clinical implication of metastasis of the ovary. Gynecol Oncol. 1995;59:124-8.

11. Vang R, Ronnet BM. Metastatic and miscellaneous primary tumors of the ovary. In Gynecologic Pathology. 1st ed. Edited by Nucci MR, Oliva E. Philadelphia: Churchill Livingstone Elsevier; 2009:539-614.

12. Losito NS, Scaffa C, Cantile M, Botti G, Costanzo R, Manna A et al. Lung cancer diagnosis on ovary mass a case report. J Ovarian Res. 2013;6:34.

13. Kim KO, Lee HY, Chun SH, Shin SJ, Kim MK, Lee $\mathrm{KH}$, et al. Clinical overview of extrapulmonary small cell carcinoma. J Korean Med Sci. 2006;21:833-7.
14. Petru E, Pickel H, Heydarfadai M, Lahousen M, Haas $\mathbf{J}$ et al. Nongenital cancer metastatic to the ovary. Gynecol Oncol. 1992;44:83-6.

15. Ketata W, Msaad. Ovarian metastases of bronchial carcinoma. Rev Respir Dis. 2011;28:101-5.

16. Balum M, Lenoir M, Ducou Le pointe H. Imaging of the ovarian mass before puberty. Arch Pediatr. 2008; 15:783-5.

17. Castadot P, Magne N, Berghmans T, Drowart A, Baeyens L, Smets D. Ovarian metastases and lung adenocarcinoma. Cancer Radiother. 2005;9:183-6.

18. Suzuki A, Yamada G, Abe S, Sato N. Napsin A is useful to distinguish primary lung adenocarcinoma from adenocarcinomas of other organs Pathol. Res Pract. 2005;6(8-9):579-86.

19. Bishop JA, Sharma R. Napsin A and thyroid transcription factor-1 expression in carcinomas of lung, breast, pancreas, kidney, thyroid. Human Pathol. 2010;6(1):20-5.

Cite this article as: Roland $\mathrm{AC}$, Didier KA, Achille K, Charles K, Joachim K, Zoly A et al. Metastatic ovarian tumor of a lung cancer at the hospital center of Chauny (France): a case report. Int J Reprod Contracept Obstet Gynecol 2017;6:4682-5. 